\title{
Causes of adult female mortality in Al Ain district, United Arab Emirates
}

\author{
C O Oyejide, A G Shalabi, M Benjawi, H Al-Hosani
}

In the Gulf countries, published data on adult mortality are limited. In the United Arab Emirates, adult plus elderly women make up $23 \%$ of the population. This study aimed at documenting trends in the levels and causes of adult female mortality in $\mathrm{Al}$ Ain district of the United Arab Emirates over a 10 year period 1984-93, thus filling a gap in the published reports and providing relevant data to public health officials for programmatic action.

Methods: Information from the vital registration system was used. Data from death certificates related to deaths of women over the age of 15 years in $\mathrm{Al}$ Ain District for the 10 years were evaluated. Causes of death were coded using the International Classification of Diseases and Related Health Problems. ${ }^{1}$ Proportional mortality ratios (PMR) were calculated for various categories of causes of death. Descriptive analyses were done using EPI INFO Version 5. The $\chi^{2}$ test for association and the $\chi^{2}$ test for trend were used, where appropriate. Student's $t$ test and analysis of variance were used for comparison of means.

Results: During the 10 years, 1036 deaths of women aged 15 years and above were registered in Al Ain District. Eighty three per cent of these deaths were from non-communicable diseases, $9.5 \%$ injuries, $6.9 \%$ infections, and $0.96 \%$ reproductive causes (table). There was an increasing trend in the PMR for noncommunicable diseases and a decreasing trend for infections $(p<0.01)$. Diseases of the circulatory system were the most common causes of death $(26 \cdot 2 \%)$, followed by malignant neoplasms $(22 \%)$, ill defined conditions $(19 \cdot 4 \%)$, and injuries $9 \cdot 5 \%$. Most common sites for malignancies included the breast $(17 \cdot 3 \%)$, stomach $(9 \cdot 7 \%)$, lymphoid + haematopoietic $(9 \cdot 3 \%)$, cervix $(8 \cdot 4 \%)$, and lungs $5 \cdot 3 \%$. In $8.8 \%$ of the malignancies the site was not stated. Sixty two per cent of the fatal injuries

UAE University
PO Box 17666

Al-Ain, United Arab

Emirates

C O Oyejide

Department of Preventive Medicine, Ministry of Health

Al-Ain, United Arab Emirates

PO Box 17666

PO Box 1766

M Benjawi

Ministry of Health,

Abu Dhabi, United

H Al-Hosani

Correspondence to:

Dr C O Oyejide.

Accepted for publication November 1995

(J Epidemiol Community Health 1996;50:224)
Age specific mortality (\%) for the causes of mortality among women in Al Ain, United Arab Emirates, 1984-93

\begin{tabular}{|c|c|c|c|c|}
\hline \multirow[t]{2}{*}{ Cause of death } & \multicolumn{4}{|c|}{ Age group } \\
\hline & $15-44 y$ & $45-59 y$ & $60+y$ & All ages \\
\hline $\begin{array}{l}\text { Non-communicable } \\
\text { diseases }\end{array}$ & $\begin{array}{l}170 \\
(63 \cdot 9)\end{array}$ & $\begin{array}{l}193 \\
(86 \cdot 9)\end{array}$ & $\begin{array}{l}492 \\
(90 \cdot 3)\end{array}$ & $\begin{array}{l}856 \\
(82 \cdot 6)\end{array}$ \\
\hline Injuries & $\begin{array}{c}60 \\
(22 \cdot 6)\end{array}$ & $\begin{array}{l}19 \\
(8.5)\end{array}$ & $\begin{array}{l}19 \\
(3 \cdot 5)\end{array}$ & $\begin{array}{l}98 \\
(9 \cdot 5)\end{array}$ \\
\hline Infections & $\stackrel{26}{(9 \cdot 8)}$ & $\begin{array}{l}11 \\
(4 \cdot 9)\end{array}$ & $\begin{array}{l}34 \\
(6 \cdot 2)\end{array}$ & $\begin{array}{l}72 \\
(6 \cdot 9)\end{array}$ \\
\hline Reproductive causes & $\begin{array}{l}10 \\
(3 \cdot 7)\end{array}$ & - & - & $\begin{array}{l}10 \\
(0.96)\end{array}$ \\
\hline Total & $\begin{array}{c}266 \\
(100)\end{array}$ & $\begin{array}{c}223 \\
(100)\end{array}$ & $\begin{array}{c}545 \\
(100)\end{array}$ & $\begin{array}{l}1036 \\
(100)\end{array}$ \\
\hline
\end{tabular}

were due to road traffic accidents. The most common site of injuries were the head and neck $(47.9 \%$ of all deaths due to accidents and injuries). Other important causes of accidental death were burns $19 \cdot 8 \%$, suicide $6 \cdot 3 \%$, electrocution $4 \cdot 2 \%$, and accidental poisoning $3.1 \%$. Ten deaths related to pregnancy were recorded during the study period, accounting for $3.8 \%$ of all deaths in women of childbearing age. There were statistically significant differences between the PMR of the disease categories and nationality $(p<0.01)$. A significantly higher proportion of deaths in Asian women compared with other nationalities was due to accidents and injuries $(p<0.01)$.

Discussion: The increasing trend in PMR for non-communicable diseases over the 10 year period can be attributed to changing lifestyles in the United Arab Emirates, and the influence of changes and improvements in diagnostic facilities. The decreasing trend in PMR for infectious diseases is due to a combination of factors including improvements in environmental conditions, health care facilities, disease notification, surveillance for infectious diseases, screening of expatriate workers, and immunisation programmes. ${ }^{2}$ The insignificant role of AIDS as a cause of mortality in this population is a major contrast to reports from other countries. ${ }^{3-5}$ Reasons for the low reproductive causes of mortality despite high parity include low rates of infectious diseases, the fact that $98 \%$ of deliveries occur in hospitals, antenatal screening for high risk conditions, and availability of emergency obstetric management. The higher proportions of accidental deaths among Asian women probably occurs because about a third of them were housemaids with greater exposure to home accidents in addition to traffic accidents.

Conclusion: Non-communicable diseases have emerged as the most common causes of adult female mortality in Al Ain; diseases of the circulatory system are the most common. There is a low level of pregnancy related mortality. Breast cancer was the most common malignancy causing mortality.

1 World Health Organization. International Classification of Diseases and Related Health Problems. 10th Revision. Volume eases and Related Health Problems. 10th Revisio

2 Ministry of Health. Annual Report. Abu Dhabi: United Arab Emirates, Ministry of Health, 1992;1-9.

3 DeCock KM, Barere B, Diaby L, et al. AIDS - The leading cause of adult death in the west African city of Abidjan, cause of adult death in the west African
Ivory Coast Science 1992;249:793-96.

4 Centers for Disease Control and Prevention/National Center 4 Centers for Disease Control and Prevention/National Center
for Health Statistics. Vital and health statistics. Mortality surveillance system: models from the second year October 1994; 39. Hyattsvill, MA: US Department of Health and Human Services, 1994;00-00. NCHS Series 20 No 22.

5 Bindels PJ, Reijneveld SA, Mulder-Felkerts DK, Coutinho $\mathrm{RA}$, van-den-Hoek AA. Impact of AIDS on premature mortality in Amsterdam 1982-1992. AIDS 1994;8(2):2337. 